\title{
OSTEOTOMY OF THE DISTAL RADIUS USING A FIXED-ANGLE VOLAR PLATE
}

Ricardo Kaempf de Oliveira', Mário Arthur Rockenbach Binz ${ }^{2}$, Marco Tonding Ferreira ${ }^{2}$, Paulo Henrique Ruschel ${ }^{3}$, Pedro Delgado Serrano ${ }^{4}$, Rafael Pêgas Praetzel ${ }^{1}$

\section{ABSTRACT}

Objective: Skewed consolidation of the distal radius, due to sequelae of fractures, may cause functional incapacity, thus leading such patients to present pain, loss of strength and diminished mobility. Based on the excellent results obtained from surgical treatment of unstable fractures of the distal radius through a volar approach and use of rigid fixation with a fixed-angle volar plate, we started to use the same method for osteotomy of the distal radius. Methods: A retrospective review was conducted, and 20 patients treated between February 2002 and October 2009 were found. The mean length of follow-up was 43.9 months (range: 12 to 96 months). The surgical indications were persistent pain, deformity and functional limitation subsequent to a dorsally displaced fracture.
Results: The mean preoperative deformity was $27^{\circ}$ of dorsal tilt of the distal radius, $87^{\circ}$ of ulnar tilt, and $7.3 \mathrm{~mm}$ of shortening of the radius. All the osteotomies consolidated and the final mean volar tilt was $6.2^{\circ}$, with ulnar tilt of $69.3^{\circ}$ and shortening of $1 \mathrm{~mm}$. The mean mobility of the wrist increased by $19.9^{\circ}$ (flexion) and by $24^{\circ}$ (extension). Mean forearm supination increased by $23.5^{\circ}$ and pronation by $21.7^{\circ}$. Grip strength increased from 13.4 to 34.5 pounds. Conclusion: Use of a fixed-angle volar plate for a volar approach towards osteotomy of the distal radius enables satisfactory correction of the deformities and eliminates the need for removal of the synthesis material caused by tendon complications

Keywords - Colles' Fracture/complications; Osteotomy/utilization; Fracture Fixation, Internal

\section{INTRODUCTION}

Fractures of the distal radius were originally described by Abraham Colles in the nineteenth century as a benign pathological condition that did not cause functional limitations, but only esthetic limitations ${ }^{(1)}$. Critical analyses on the results from conservative treatment of these fractures, conducted by DePalma in the 1950s, Frykman in the 1960s and Cooney in the 1980 s, demonstrated that there was a high rate of unsatisfactory results. Poor results were found in the cases of more than $30 \%$ of the patients in these series, and most of these were related to skewed consolidation $^{(2)}$. Several authors have now demonstrated the possible sequelae that may occur when such fractures are not treated correctly ${ }^{(3)}$.
Conservative treatment is still widely used, particularly in cases of non-displaced extra-articular fractures and in stable displaced factures after reduction that do not require immobilization in uncomfortable positions of flexion and ulnar deviation of the wrist. Nonetheless, these fractures may displace secondarily, thus gradually losing the reduction that was obtained in the emergency treatment ${ }^{(4,5)}$. Skewed consolidation is the most frequent complication following fractures of the distal radius, presenting variable prevalence that ranges from five to $70 \%$ of the cases ${ }^{(3,6)}$.

Skewed consolidation of the distal radius can be divided into extra-articular, intra-articular and combined (intra and extra-articular) ${ }^{(6)}$. The definition of

1 - Orthopedist in the Hand Group, Santa Casa de Porto Alegre, Porto Alegre, RS, Brazil.

2 - Resident Physician in Orthopedics, Santa Casa de Porto Alegre, Porto Alegre, RS, Brazil

3 - Orthopedist and Head of the Hand Group, Santa Casa de Porto Alegre, Porto Alegre, RS, Brazil.

4 - Orthopedist at Hospital Fremap, Madrid, Spain.

Work performed at the Santa Casa Hospital Complex and Hospital Mãe de Deus, Porto Alegre, RS.

Correspondence: Rua Leopoldo Bier 825, sala 301, Santana, 90620-100 Porto Alegre, RS. E-mail: ricardokaempf@gmail.com.br

Work received for publication: February 23, 2011; accepted for publication: August 8, 2011.

The authors declare that there was no conflict of interest in conducting this work 
intra-articular skewed consolidation was determined by Knirk and Jupiter as a joint step of more than $2 \mathrm{~mm}$, which is a situation that is considered to present a risk of development of arthrosis ${ }^{(7)}$. In cases of extra-articular skewed consolidation, the definition is based on the angle and shortening of the distal radius. The wide range of prevalence of skewed consolidation $(5-70 \%)$ is due to the disparity of the criteria for defining it. Small changes in the orientation of joint surfaces and length and/or rotational discrepancies should not strictly be considered to be skewed consolidation, since these do not give rise to significant deformities or functional repercussions. They should therefore be excluded from this definition ${ }^{(7,8)}$.

Approximately $25 \%$ of distal radius fractures that are treated orthopedically present secondary misalignment that evolves into skewed consolidation ${ }^{(9,10)}$. With the development of fixation systems, this rate was reduced to $10 \%$, although $80 \%$ of corrective osteotomy procedures are carried out on fractures that were initially treated orthopedically (i.e. conservatively $)^{(9,11,12)}$.

Skewed consolidation of distal radius fractures alters the normal function of the radiocarpal distal radioulnar joints ${ }^{(13)}$. Shortening and loss of volar tilt of the radius give rise to loss of strength, diminished mobility, deformity and pain ${ }^{(14)}$. Loss of radial tilt greater than $20^{\circ}$ in the sagittal plane, $10^{\circ}$ in the coronal plane, rotation greater than $10^{\circ}$ or shortening greater than $4 \mathrm{~mm}$ may produce symptomatic alterations, with indication of surgical correction ${ }^{(15)}$.

The objective of osteotomy is to modify the orientation of the wrist, thus enabling, through bone realignment, homogenous distribution of forces and normal kinematics of the radiocarpal, mediocarpal and distal radioulnar joints.

The results from distal osteotomy of the radius performed because of skewed consolidation are better in patients with extra-articular deformity $(80 \%$ of the results are good and excellent), with good preoperative mobility ( $70 \%$ mobility compared with the contralateral side), without degenerative joint abnormalities, with good mediocarpal alignment and with radial shortening less than $10 \mathrm{~mm}^{(8)}$.

Osteotomy of the distal radius is contraindicated for patients with few symptoms, even if they present severe radiographic abnormalities. These patients are generally elderly and make low functional demands.
It is also contraindicated for patients with irreducible mediocarpal instability, mediocarpal arthrosis and signs of sympathetic reflex dystrophy ${ }^{(6)}$.

There are several studies on the clinical and radiological results from surgical treatment of this deformity. However, these are very heterogenous series, with results that do not focus much on functional evolution.

In the present study, we analyze the clinical and radiological results from surgical treatment of skewed consolidation of the distal radius by means of extra-articular osteotomy in the form of an addition wedge, using a volar approach and fixation with a fixed-angle plate.

\section{MATERIAL AND METHOD}

All the patients who underwent corrective surgery for skewed consolidation of the distal radius at the Orthopedics and Traumatology Service of Santa Casa Hospital and Hospital Mãe de Deus, Porto Alegre, RS, between February 2002 and October 2009, were evaluated retrospectively. This study was analyzed and authorized by the ethics committee of our hospital.

The criteria for indicating surgery were persistent pain, loss of mobility, unacceptable radiographic parameters, functional limitation and incapacity to return to previous professional activities. The exclusion criteria were taken to be presence of mild radiological deformities, degenerative joint abnormalities and clinical signs of sympathetic-reflex dystrophy. Osteopenia and osteoporosis were not considered to be contraindications, since diminished bone quality is common among patients with sequelae from distal radius fractures. Patients with incomplete follow-up and follow-up of less than 12 months were also excluded from the study.

Out of a total of 32 patients who underwent operations to treat skewed consolidation of the distal radius, 20 patients (14 women and six men) were included in this study because they underwent extra-articular osteotomy with a volar approach. The patients are presented in Tables 1 and 2 .

The patients' mean age was 57.9 years (ranging from 39 to 72 years). The left side was more affected (11 patients), and the other nine patients were affected on the right side. Most of the patients (17) were treated for an extra-articular fracture of the distal radius orthopedically (i.e. conservatively). The other three patients initially underwent closed reduction and 
Table 1 - Epidemiology and preoperative data.

\begin{tabular}{|c|c|c|c|c|c|c|c|c|c|c|c|}
\hline & \multirow{4}{*}{ Sex } & \multirow{4}{*}{ Age (years) } & \multirow{4}{*}{ Side } & \multirow{4}{*}{ Occupation } & \multicolumn{3}{|c|}{ Preoperative X-ray } & \multicolumn{3}{|c|}{ Preoperative function } & \multirow{4}{*}{ Pain scale } \\
\hline & & & & & Dorsal & & \multirow{3}{*}{$\begin{array}{c}\text { Radial } \\
\text { shortening }\end{array}$} & \multirow{3}{*}{\begin{tabular}{|c|} 
Flexion/ \\
Extension \\
\end{tabular}} & \multirow{3}{*}{$\begin{array}{l}\text { Pronation/ } \\
\text { Supination }\end{array}$} & \multirow{3}{*}{ Strength } & \\
\hline & & & & & Tilt & UInar Tilt & & & & & \\
\hline & & & & & & & & & & & \\
\hline 1 & $\mathrm{~F}$ & 69 & $\mathrm{D}$ & Retired & $30^{\circ}$ & $80^{\circ}$ & $9 \mathrm{~mm}$ & $20^{\circ} / 30^{\circ}$ & $70^{\circ} / 65^{\circ}$ & $18 \mathrm{Lbs}$ & 9 \\
\hline 2 & $\mathrm{~F}$ & 62 & $E$ & Retired & $35^{\circ}$ & $95^{\circ}$ & $7 \mathrm{~mm}$ & $25^{\circ} / 40^{\circ}$ & $55^{\circ} / 40^{\circ}$ & 20 Lbs & 8 \\
\hline 3 & $\mathrm{M}$ & 55 & $\mathrm{E}$ & Bank worker & $25^{\circ}$ & $88^{\circ}$ & $8 \mathrm{~mm}$ & $35^{\circ} / 40^{\circ}$ & $60^{\circ} / 50^{\circ}$ & 10 Lbs & 7 \\
\hline 4 & $\mathrm{~F}$ & 56 & $E$ & Retired & $15^{\circ}$ & $95^{\circ}$ & $6 \mathrm{~mm}$ & $23^{\circ} / 33^{\circ}$ & $75^{\circ} / 60^{\circ}$ & 15 Lbs & 9 \\
\hline 5 & $\mathrm{~F}$ & 42 & $\mathrm{D}$ & Nurse & $20^{\circ}$ & $76^{\circ}$ & $9 \mathrm{~mm}$ & $25^{\circ} / 40^{\circ}$ & $65^{\circ} / 55^{\circ}$ & 19 Lbs & 7 \\
\hline 6 & $\mathrm{~F}$ & 65 & $\mathrm{D}$ & Retired & $40^{\circ}$ & $97^{\circ}$ & $6 \mathrm{~mm}$ & $20^{\circ} / 35^{\circ}$ & $60^{\circ} / 40^{\circ}$ & 18 Lbs & 8 \\
\hline 7 & $\mathrm{~F}$ & 72 & $E$ & Retired & $35^{\circ}$ & $84^{\circ}$ & $7 \mathrm{~mm}$ & $30^{\circ} / 40^{\circ}$ & $45^{\circ} / 50^{\circ}$ & 12 Lbs & 8 \\
\hline 8 & $M$ & 52 & $\mathrm{D}$ & Trader & $20^{\circ}$ & $95^{\circ}$ & $10 \mathrm{~mm}$ & $15^{\circ} / 30^{\circ}$ & $50^{\circ} / 40^{\circ}$ & 17 Lbs & 7 \\
\hline 9 & $\mathrm{~F}$ & 57 & $E$ & Retired & $25^{\circ}$ & $77^{\circ}$ & $7 \mathrm{~mm}$ & $22^{\circ} / 34^{\circ}$ & $55^{\circ} / 50^{\circ}$ & 12 Lbs & 9 \\
\hline 10 & $\mathrm{~F}$ & 58 & $E$ & Psychologist & $35^{\circ}$ & $93^{\circ}$ & $6 \mathrm{~mm}$ & $20^{\circ} / 35^{\circ}$ & $45^{\circ} / 40^{\circ}$ & 9 Lbs & 8 \\
\hline 11 & $\mathrm{~F}$ & 72 & $\mathrm{D}$ & Retired & $20^{\circ}$ & $86^{\circ}$ & $9 \mathrm{~mm}$ & $18^{\circ} / 28^{\circ}$ & $60^{\circ} / 35^{\circ}$ & 19 Lbs & 7 \\
\hline 12 & $\mathrm{~F}$ & 68 & $E$ & Retired & $30^{\circ}$ & $87^{\circ}$ & $7 \mathrm{~mm}$ & $30^{\circ} / 50^{\circ}$ & $70^{\circ} / 50^{\circ}$ & 13 Lbs & 9 \\
\hline 13 & $M$ & 61 & $E$ & Stonemason & $25^{\circ}$ & $91^{\circ}$ & $5 \mathrm{~mm}$ & $27^{\circ} / 35^{\circ}$ & $60^{\circ} / 40^{\circ}$ & 17 Lbs & 9 \\
\hline 14 & $\mathrm{~F}$ & 66 & $\mathrm{D}$ & Retired & $30^{\circ}$ & $87^{\circ}$ & $7 \mathrm{~mm}$ & $19^{\circ} / 36^{\circ}$ & $50^{\circ} / 40^{\circ}$ & 10 Lbs & 8 \\
\hline 15 & $M$ & 46 & $E$ & Lawyer & $40^{\circ}$ & $82^{\circ}$ & $9 \mathrm{~mm}$ & $25^{\circ} / 40^{\circ}$ & $55^{\circ} / 45^{\circ}$ & 8 Lbs & 9 \\
\hline 16 & $\mathrm{M}$ & 39 & $\mathrm{D}$ & Electrician & $15^{\circ}$ & $98^{\circ}$ & $10 \mathrm{~mm}$ & $20^{\circ} / 45^{\circ}$ & $70^{\circ} / 60^{\circ}$ & $11 \mathrm{Lbs}$ & 7 \\
\hline 17 & $\mathrm{M}$ & 45 & $E$ & Dentist & $25^{\circ}$ & $85^{\circ}$ & $4 \mathrm{~mm}$ & $30^{\circ} / 35^{\circ}$ & $45^{\circ} / 40^{\circ}$ & 12 Lbs & 7 \\
\hline 18 & $\mathrm{~F}$ & 65 & $\mathrm{D}$ & Retired & $35^{\circ}$ & $74^{\circ}$ & $6 \mathrm{~mm}$ & $21^{\circ} / 32^{\circ}$ & $70^{\circ} / 45^{\circ}$ & 8 Lbs & 9 \\
\hline 19 & $\mathrm{~F}$ & 61 & $\mathrm{D}$ & Retired & $20^{\circ}$ & $78^{\circ}$ & $7 \mathrm{~mm}$ & $18^{\circ} / 38^{\circ}$ & $50^{\circ} / 40^{\circ}$ & 9 Lbs & 8 \\
\hline 20 & $\mathrm{~F}$ & 48 & $E$ & Housewife & $25^{\circ}$ & $93^{\circ}$ & $8 \mathrm{~mm}$ & $20^{\circ} / 30^{\circ}$ & $55^{\circ} / 50^{\circ}$ & 11 Lbs & 9 \\
\hline
\end{tabular}

percutaneous fixation using Kirschner wires. In all the cases, the fractures were Fernandez type $\mathrm{I}^{(16)}$ and extra-articular ${ }^{(17)}$.

With regard to occupation, retired individuals predominated in our sample, forming $55 \%$ of the population.

All the patients were treated for their initial fracture in other clinics or hospitals, and were referred to our service because of their deformities and residual symptoms (Figures 1 and 2).

The most frequent complaints among the patients were pain and loss of mobility, followed by esthetic deformity, loss of strength and numbness in the areas innervated by the median nerve. All the patients presented diminished mobility at the preoperative assessment (Figure $3-\mathrm{A}, \mathrm{B}, \mathrm{C}$ and D). The mean extension was $36.3^{\circ}$ (range: $28-50^{\circ}$ ) and the mean flexion was $23.1^{\circ}$ (range: $15-35^{\circ}$ ). The mean supination was $46.7^{\circ}$ (range: $35-65^{\circ}$ ) and the mean pronation was $58.2^{\circ}$ (range: $45-75^{\circ}$ ).

Grip strength was measured using a Jamar dynamometer placed at setting 3 . The mean before surgery was 13.4 pounds (lbs) (range: $8-20 \mathrm{lbs}$ ). Among the 20 patients, four underwent carpal tunnel release during the same surgical procedure as the osteotomy. The mean time that elapsed between the fracture and the osteotomy was nine months (range: 3-38 months). The mean duration of the follow-up after the osteotomy was 43.9 months (range: 12-96 months).

Our retrospective review analyzed the clinical and radiological results and the possible complications consequent to the surgery. The clinical analysis was performed using a visual analogue scale (0-10; in which 0 signified absence of pain and 10 was the worst pain that could be felt), wrist and forearm mobility assessment, grip strength and the DASH questionnaire, applied before and after the operation.

By means of wrist radiographs in posteroanterior and lateral view, the following radiographic parameters of the distal radius were analyzed: radial tilt, volar angle and shortening of the radius (ulnar variance). The time taken for consolidation of the osteotomy to be achieved was also determined from radiographs.

The synthesis material used varied according to the surgeon's choice and the health insurance funding that was released. All the fixation systems used the same principle of locked plates, with distal pins at fixed angles. The Synthes volar fixation system was used for $35 \%$ of the patients, the GMReis PBA system for $35 \%$, the Engiplan volar plate for $20 \%$, and the Johnson and Johnson DVR plate for $10 \%$. 
Table 2 - Postoperative data.

\begin{tabular}{|c|c|c|c|c|c|c|c|c|c|c|}
\hline & \multirow{4}{*}{ Plate } & \multirow{4}{*}{$\begin{array}{l}\text { Follow-up } \\
\text { (months) }\end{array}$} & \multirow{4}{*}{$\begin{array}{l}\text { Consolidation } \\
\text { (weeks) }\end{array}$} & \multicolumn{3}{|c|}{ Postoperative X-ray } & \multicolumn{3}{|c|}{ Postoperative function } & \multirow{4}{*}{$\begin{array}{l}\text { Pain } \\
\text { scale }\end{array}$} \\
\hline & & & & \multirow{3}{*}{ Volar angle } & \multirow{3}{*}{ Ulnar angle } & \multirow{3}{*}{$\begin{array}{c}\text { Radial } \\
\text { shortening }\end{array}$} & \multirow{3}{*}{\begin{tabular}{|c|} 
Flexion/ \\
Extension \\
\end{tabular}} & \multirow{3}{*}{\begin{tabular}{|l|} 
Pronation/ \\
Supination \\
\end{tabular}} & \multirow{3}{*}{ Grip } & \\
\hline & & & & & & & & & & \\
\hline & & & & & & & & & & \\
\hline 1 & Synthes & 96 & 8 & $5^{\circ}$ & $65^{\circ}$ & $2 \mathrm{~mm}$ & $40^{\circ} / 60^{\circ}$ & $85^{\circ} / 80^{\circ}$ & 26 Lbs & 3 \\
\hline 2 & $\begin{array}{c}\text { PBA } \\
\text { G M Reis }\end{array}$ & 60 & 7 & $2^{\circ}$ & $75^{\circ}$ & $2 \mathrm{~mm}$ & $40^{\circ} / 50^{\circ}$ & $85^{\circ} / 75^{\circ}$ & 30 Lbs & 1 \\
\hline 3 & Synthes & 84 & 9 & $1^{\circ}$ & $68^{\circ}$ & $3 \mathrm{~mm}$ & $45^{\circ} / 55^{\circ}$ & $80^{\circ} / 70^{\circ}$ & 45 Lbs & 4 \\
\hline 4 & $\begin{array}{c}\text { PBA } \\
\text { G M Reis }\end{array}$ & 90 & 6 & $5^{\circ}$ & $75^{\circ}$ & $0 \mathrm{~mm}$ & $50^{\circ} / 65^{\circ}$ & $90^{\circ} / 80^{\circ}$ & 25 Lbs & 1 \\
\hline 5 & \begin{tabular}{|c|} 
PBA \\
G M Reis \\
\end{tabular} & 72 & 16 & $1^{\circ}$ & $65^{\circ}$ & $0 \mathrm{~mm}$ & $40^{\circ} / 55^{\circ}$ & $80^{\circ} / 70^{\circ}$ & 30 Lbs & 2 \\
\hline 6 & \begin{tabular}{|c|} 
DVR \\
Hand Innovations \\
\end{tabular} & 18 & 8 & $2^{\circ}$ & $67^{\circ}$ & $1 \mathrm{~mm}$ & $45^{\circ} / 55^{\circ}$ & $80^{\circ} / 65^{\circ}$ & 35 Lbs & 3 \\
\hline 7 & Engiplan & 36 & 9 & $5^{\circ}$ & $70^{\circ}$ & $2 \mathrm{~mm}$ & $50^{\circ} / 70^{\circ}$ & $75^{\circ} / 65^{\circ}$ & 28 Lbs & 1 \\
\hline 8 & $\begin{array}{c}\text { PBA } \\
\text { G M Reis }\end{array}$ & 40 & 7 & $9^{\circ}$ & $75^{\circ}$ & $3 \mathrm{~mm}$ & $40^{\circ} / 60^{\circ}$ & $80^{\circ} / 75^{\circ}$ & 37 Lbs & 2 \\
\hline 9 & Engiplan & 70 & 8 & $3^{\circ}$ & $67^{\circ}$ & $0 \mathrm{~mm}$ & $43^{\circ} / 57^{\circ}$ & $80^{\circ} / 80^{\circ}$ & 30 Lbs & 3 \\
\hline 10 & $\begin{array}{c}\text { DVR } \\
\text { Hand Innovations } \\
\end{array}$ & 10 & 10 & $10^{\circ}$ & $65^{\circ}$ & $1 \mathrm{~mm}$ & $40^{\circ} / 60^{\circ}$ & $75^{\circ} / 70^{\circ}$ & 40 Lbs & 4 \\
\hline 11 & \begin{tabular}{|l|} 
Engiplan \\
\end{tabular} & 30 & 6 & $7^{\circ}$ & $70^{\circ}$ & $0 \mathrm{~mm}$ & $30^{\circ} / 45^{\circ}$ & $80^{\circ} / 60^{\circ}$ & 28 Lbs & 2 \\
\hline 12 & Synthes & 60 & 9 & $4^{\circ}$ & $65^{\circ}$ & $1 \mathrm{~mm}$ & $50^{\circ} / 65^{\circ}$ & $85^{\circ} / 70^{\circ}$ & 47 Lbs & 2 \\
\hline 13 & Synthes & 24 & 10 & $12^{\circ}$ & $75^{\circ}$ & $2 \mathrm{~mm}$ & $45^{\circ} / 65^{\circ}$ & $80^{\circ} / 70^{\circ}$ & 32 Lbs & 3 \\
\hline 14 & $\begin{array}{c}\text { PBA } \\
\text { G M Reis }\end{array}$ & 42 & 7 & $5^{\circ}$ & $73^{\circ}$ & $2 \mathrm{~mm}$ & $40^{\circ} / 50^{\circ}$ & $85^{\circ} / 70^{\circ}$ & 30 Lbs & 2 \\
\hline 15 & $\begin{array}{c}\text { PBA } \\
\text { G M Reis }\end{array}$ & 36 & 7 & $13^{\circ}$ & $68^{\circ}$ & $0 \mathrm{~mm}$ & $45^{\circ} / 65^{\circ}$ & $70^{\circ} / 65^{\circ}$ & 53 Lbs & 1 \\
\hline 16 & $\begin{array}{c}\text { PBA } \\
\text { G M Reis }\end{array}$ & 24 & 8 & $6^{\circ}$ & $75^{\circ}$ & $1 \mathrm{~mm}$ & $40^{\circ} / 65^{\circ}$ & $90^{\circ} / 85^{\circ}$ & 48 Lbs & 3 \\
\hline 17 & Synthes & 18 & 10 & $4^{\circ}$ & $71^{\circ}$ & $2 \mathrm{~mm}$ & $55^{\circ} / 70^{\circ}$ & $85^{\circ} / 70^{\circ}$ & 33 Lbs & 2 \\
\hline 18 & Synthes & 36 & 8 & $10^{\circ}$ & $69^{\circ}$ & $3 \mathrm{~mm}$ & $40^{\circ} / 60^{\circ}$ & $80^{\circ} / 70^{\circ}$ & 27 Lbs & 4 \\
\hline 19 & $\begin{array}{c}\text { PBA } \\
\text { G M Reis }\end{array}$ & 12 & 11 & $2^{\circ}$ & $67^{\circ}$ & $0 \mathrm{~mm}$ & $45^{\circ} / 65^{\circ}$ & $65^{\circ} / 55^{\circ}$ & 32 Lbs & 1 \\
\hline 20 & Synthes & 20 & 7 & $9^{\circ}$ & $62^{\circ}$ & $0 \mathrm{~mm}$ & $50^{\circ} / 70^{\circ}$ & $70^{\circ} / 60^{\circ}$ & 34 Lbs & 2 \\
\hline
\end{tabular}

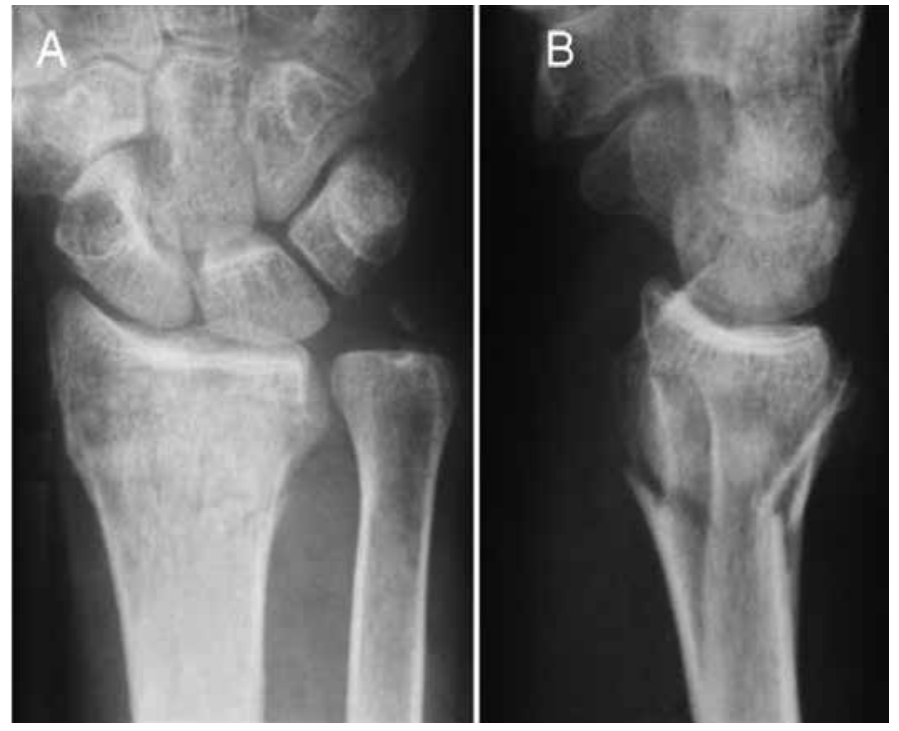

Figure 1 - 62-year-old female patient presenting fracture of the distal third of the radius: anteroposterior $(A)$ and lateral $(B)$ radiographs with dorsal angle, shortening and signs of instability. Initially treated with reduction and plaster cast immobilization.

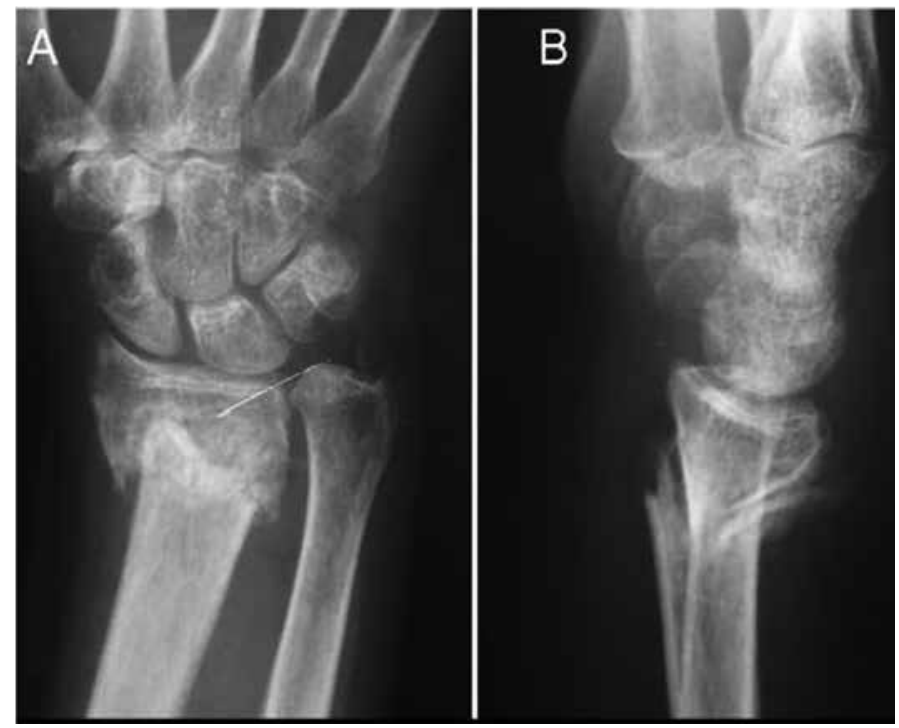

Figure 2 - Four months after orthopedic (conservative) treatment: note skewed consolidation with severe shortening of the distal radius (6 $\mathrm{mm}$ ) on anteroposterior radiograph $(A)$ and dorsal angle (35 degrees) on lateral view (B). 


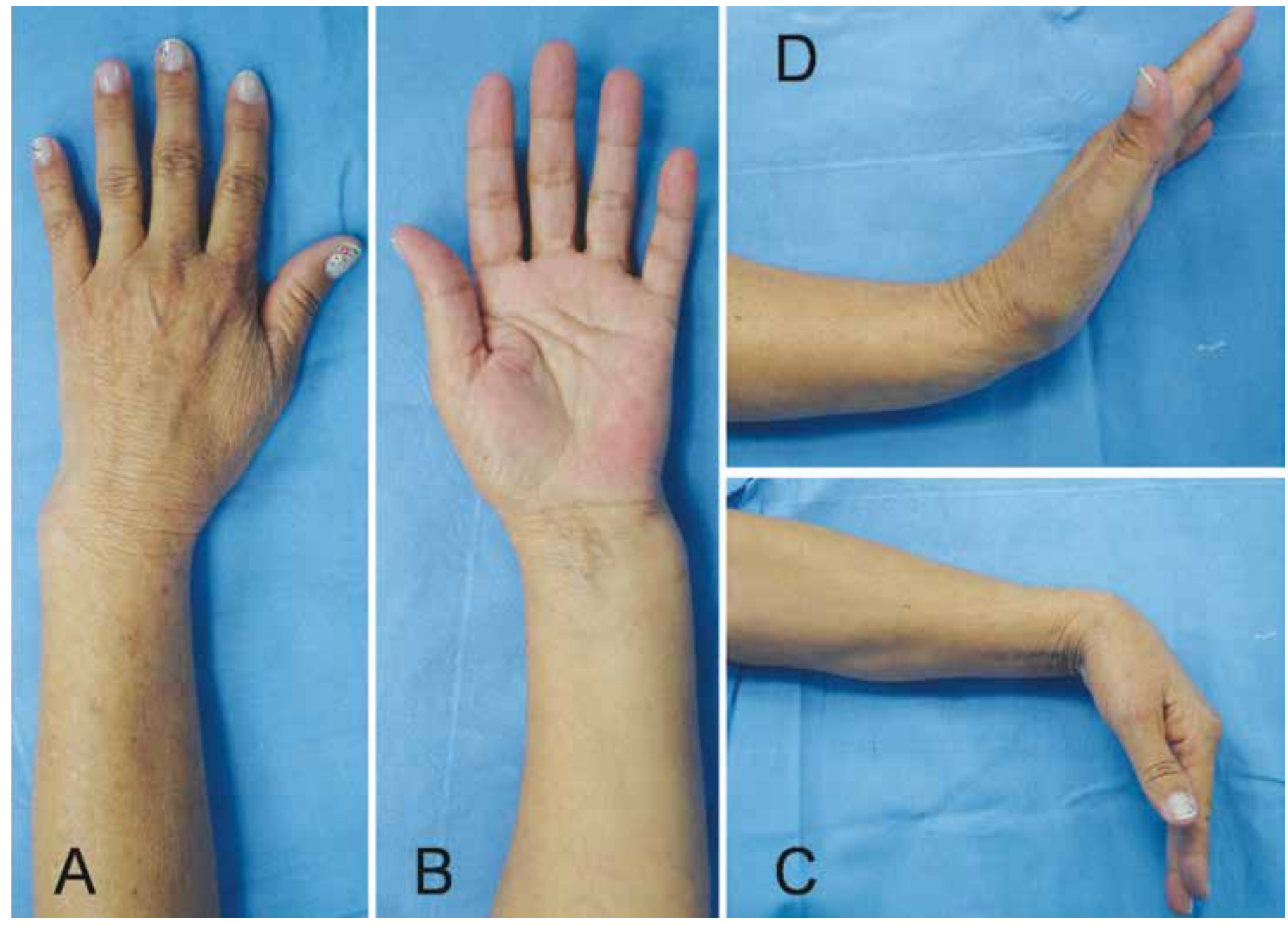

Figure 3 - After conservative treatment, the patient presented pain at the fracture site, deformity $(A$ and $B)$ and diminished movement, while flexion was maintained (C). Note the greater loss of extension (D).

Post-traumatic wrist arthrosis seen on pre and postoperative radiographs was graded according to the criteria of Knirk and Jupiter ${ }^{(7)}$. Mild arthrosis was defined as a small decrease in the joint space; moderate arthrosis as an evident decrease in the joint space and presence of osteophytes; and severe arthrosis as alteration and complete loss of the joint space and presence of osteophytes and subchondral cysts. None of the patients presented signs of arthrosis on the preoperative radiographs.

The statistical analysis was performed by comparing the preoperative parameters of pain, mobility, radiographic data, strength and DASH with the same parameters after the operation to correct the skewed consolidation of the distal radius by means of extra-articular osteotomy with a volar approach, using the SPSS statistical test. The quantitative variables were investigated regarding whether they were of parametric nature using the Kolmogorov-Smirnov test. To evaluate the means from the pre and postoperative results, the paired Student t test was used.

\section{SURGICAL TECHNIQUE}

In first place, planning for osteotomy should be done outside of the time of the surgery. Posteroanterior and lateral radiographs of both wrists are produced, and drawings are made to observe the correct site for the osteotomy and the degree of correction necessary, which will determine the positioning of the plate and the quantity of bone graft (Figure $4-\mathrm{A}$ and B).

Once in the surgical theater, the patient is firstly positioned in dorsal decubitus and a pneumatic tourniquet is set up on the affected upper limb. The wing of the contralateral iliac is prepared for bone graft harvesting. This facilitates the procedure, because a second surgical team can harvest the bone graft during the procedure on the wrist. 


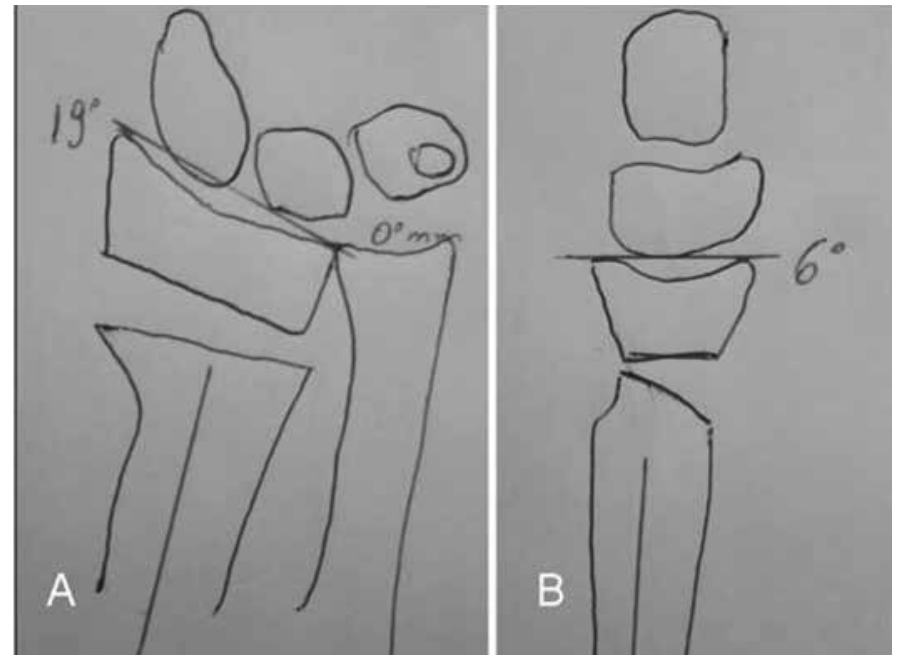

Figure 4 - Planning for osteotomy by means of trial and error method. Through comparison with a radiograph of the contralateral wrist, it was possible to predict the amount of angling and stretching needed to achieve correct bone positioning.

The approach taken for the wrist is from the extended flexor carpi radialis $(\mathrm{FCR})^{(18)}$. A longitudinal volar cutaneous incision is made above the distal portion of the FCR tendon. A Z-shaped break in the incision is made when crossing the flexion crease of the wrist. After making the incision in the skin and subcutaneous cellular tissue, the superficial and deep portions of the FCR tendon sheath are then opened and moved away to the medial side, thereby protecting the median nerve. Going in deeper, the Parona space is encountered, and an incision is made in the pronator quadratus muscle, to elevate it in an L-shape. In this manner, the distal and radial portions of the muscle are deinserted and the muscle belly is pushed out medially, thus preserving its vascularization coming from interosseous arteries. Once this has been done, the volar osseous portion of the distal radius is reached (Figure $5-\mathrm{A}, \mathrm{B}$ and $\mathrm{C}$ ).

After this stage, the radial septum is released. This is a structure formed by the combined insertion of the tendon of the brachioradial muscle and the first extensor compartment ${ }^{(19)}$. This facilitates the release and future positioning of the metaphysis and epiphysis of the radius. Tenotomy and stretching of the brachioradial muscle also makes it easier to maintain the bone reduction, since this removes one of the deforming factors relating to flexion and radial deviation of the distal portion of the radius.

Through this approach, the stage of osteotomy itself is reached. To correctly plan and position the osteotomy site, Kirschner wires are put in place, and these serve as guides for the osteotomy. It is done $1.5 \mathrm{~cm}$ proximally to the joint, and following the joint surface, both in lateral and in anteroposterior projection. This provides enough space to position the plate. The osteotomy is generally performed at the site of the initial fracture.

Once the osteotomy has been done, the cut in the bone makes it possible to pronate the diaphysis (proximal fragment) of the radius, thereby allowing access to the posterior portion of the wrist. At this time, the portion of the dorsal periosteum of the radius that became shortened and thickened due to the skewed consolidation of the fracture should be resected. If the periosteum is not released, correct positioning of the distal fragment of the radius becomes impossible (Figure 6-A and B).

Correct positioning of the epiphysis of the radius is achieved with the aid of a lamina spreader, which is placed on the most radial and dorsal portion of the bone. This helps to stretch and angle the distal fragment of the radius, while the osteotomy is fixed using the plate (Figure $7-\mathrm{A}, \mathrm{B}$ and C). In some cases, the technique described by Prommersberger is used. In this, the distal extremity of the radius is firstly fixed by means of a fixed-angle implant that already is set at the desired corrected angle, and then the plate is used as a fulcrum for stretching and angling the distal epiphysis of the radius ${ }^{(20)}$.

Fixation of the osteotomy is done using a fixed-angle volar plate. This type of plate was initially designed for fixation of distal fractures of the radius and its use was expanded to include fixation of distal osteotomy of the radius. Application of the volar plate to the distal radius automatically corrects the pronated deformity of the distal fragment.

This type of plate fixes the distal bone fragment by means of locking pins that provide subchondral support. The distal pins are inserted individually with the aid of a guide that is fixed to the plate. When fixed the plate, they are incorporated into its structure. Because the distal pins are located juxta-proximally to the subchondral bone, they have the function of providing support and neutralizing the forces exerted on the joint fragment, thereby impeding displacement after the correct alignment of the distal radius has been achieved ${ }^{(4,9)}$. Each pin is angled differently, to follow the anatomical angulation of the distal radius. After the first pin has been inserted, radiographic confirmation of its correct positioning is required in order to avoid placement of pins inside the joint. Proximal bone fixation is achieved by means of $3.5 \mathrm{~mm}$ screws (Figure $8-\mathrm{A}$ and $\mathrm{B}$ ). 


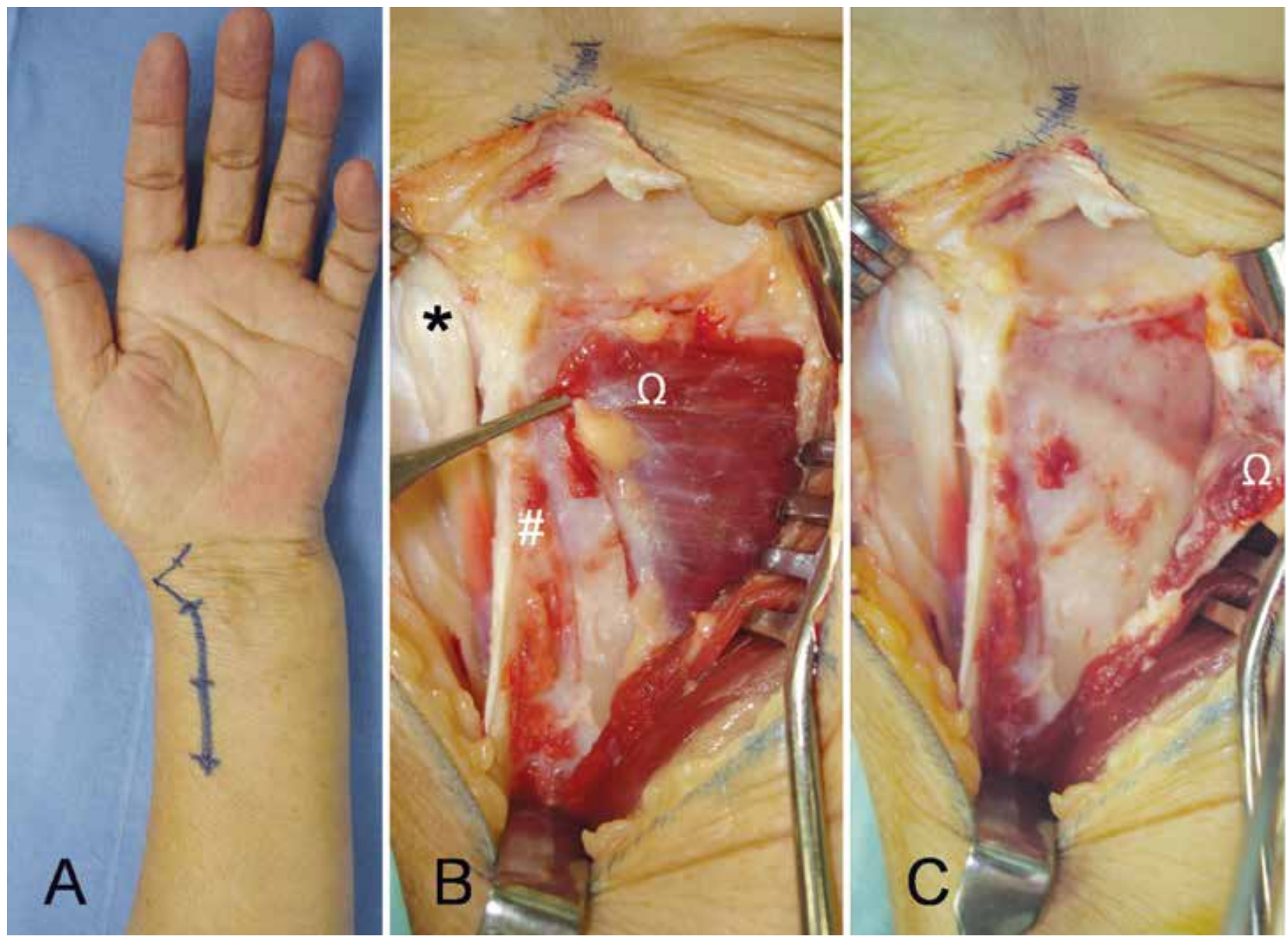

Figure 5 - Incision of 8 to $10 \mathrm{~cm}$ above the radial flexor of the carpus in order to access the distal radius (A). In Figure B, after approaching and penetrating the Parona space, the tendons of the first extensor compartment $\left(^{*}\right)$, the brachioradial tendon (\#) and the pronator quadratus muscle $(\Omega)$ could be seen. In Figure C, the pronator quadratus is elevated in an L-shape, thereby giving access to the distal portion of the radius.

After placement of all of the pins and screws, the cortical-spongy bone graft that was harvested from the iliac wing is implanted. This does not have a mechanical or structural function but, rather, the function of stimulating bone consolidation in a rapid manner (osteoinduction).

After this, the plate and bone graft are covered by reinserting the pronator quadratus and thus separating them from the flexor tendons. Complementary osteosynthesis methods with Kirschner wires or external fixators do not need to be used (Figure $9-\mathrm{A}$ and $\mathrm{B}$ ).

Osteotomy to shorten the ulna ${ }^{(21)}$ can be performed in cases of severe shortening of the radius (more than $4 \mathrm{~mm}$ ). This facilitates reduction of the radioulnar joint and diminished the quantity of bone graft needed. Despite this criterion, no additional procedure was performed on the radioulnar joint in our series of patients, or any shortening of the ulna.
The postoperative management for our patients consisted of immediate stimulation of active mobilization of the fingers and elevation of the operated limb. The radiocarpal joint was immobilized for three to four weeks, using a plaster-cast splint going from the forearm to the palm, while leaving the metacarpal-phalangeal joints free. Twenty days after the operation, the patients were released to perform tasks of daily living, but without applying force using the operated upper limb. The patients were released to use the upper limb without protection only after radiographic bone consolidation had been achieved.

For all the procedures performed, informed consent was obtained from the patient. During the immediate postoperative period, the patients received prophylaxis against infection using cefazolin ( 2 g every 8 hours) for a total of 24 hours. 

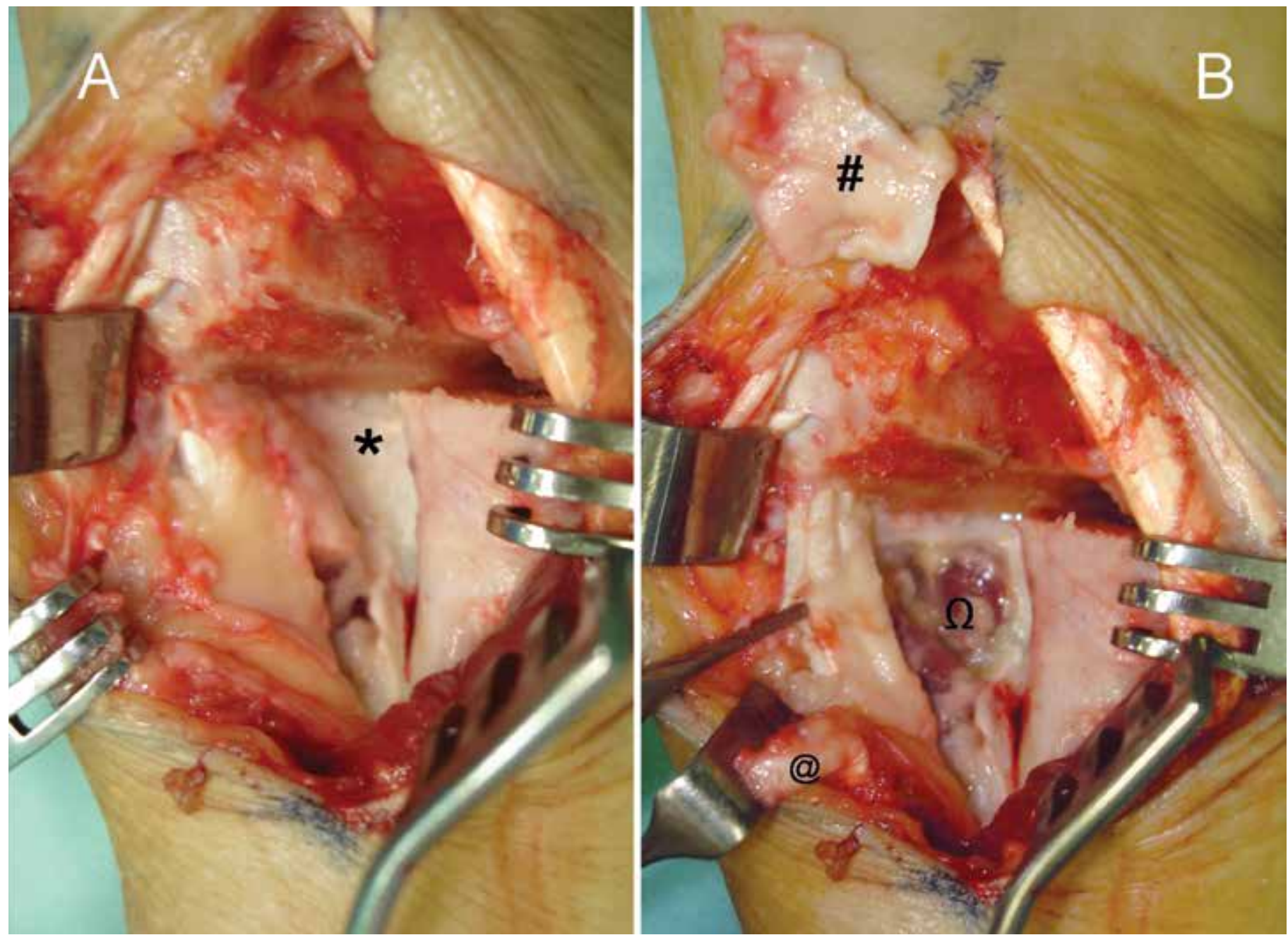

Figure 6 - Osteotomy performed one centimeter proximally to the joint surface (A). After pronation of the radial diaphysis, the dorsal periosteum can be accessed, which is thickened because of consolidation of the fracture $\left({ }^{*}\right)$. In Figure $B$, after resection of the dorsal periosteum (\#), thereby enabling correct positioning and stretching of the distal radius, the extensor tendons of the fingers can be seen $(\Omega)$. In the same photo, the brachioradial tendon after Z-shaped stretching can be seen (@).
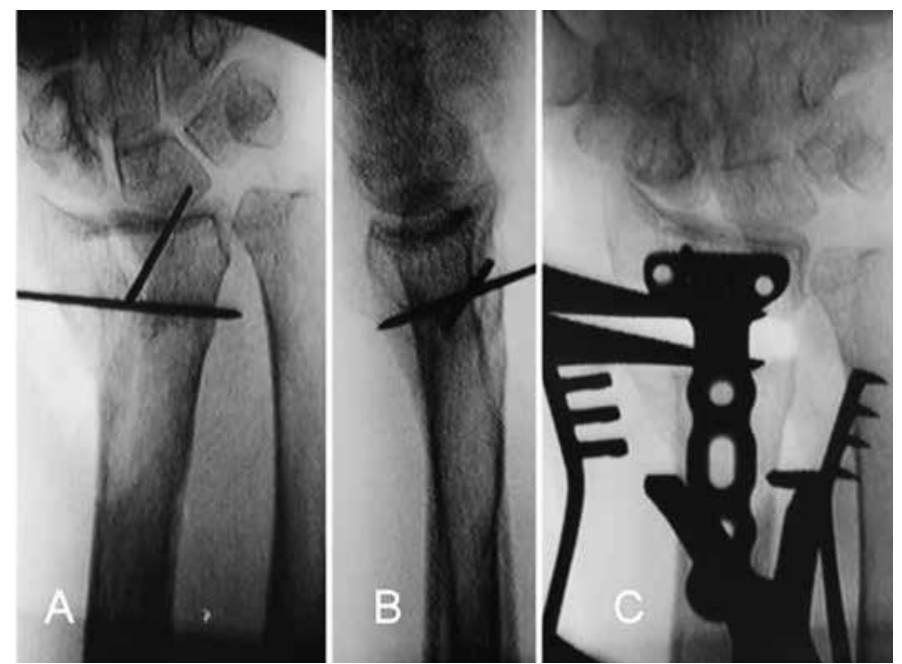

Figure 7 - Marking of the site for the osteotomy with placement of two Kirschner wires, $1 \mathrm{~cm}$ from the joint, in both radiographic views (anteroposterior $(A)$ and lateral $(B)$ ). After the osteotomy had been performed, tweezers (lamina spreaders) were placed on the dorsal-radial portion of the bone. This enables stretching and correct positioning of the joint surface.

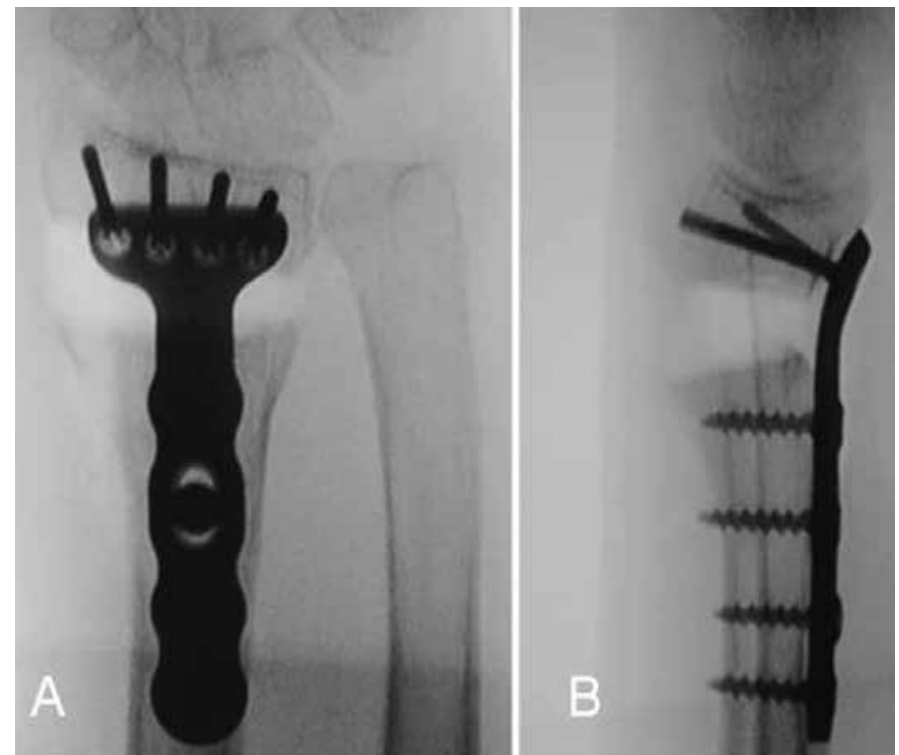

Figure 8 - Radiographs in anteroposterior view $(\mathrm{A})$ and lateral view $(B)$ during the operation, showing the correct positioning and fixation of the osteotomy with a fixed-angle volar plate. 


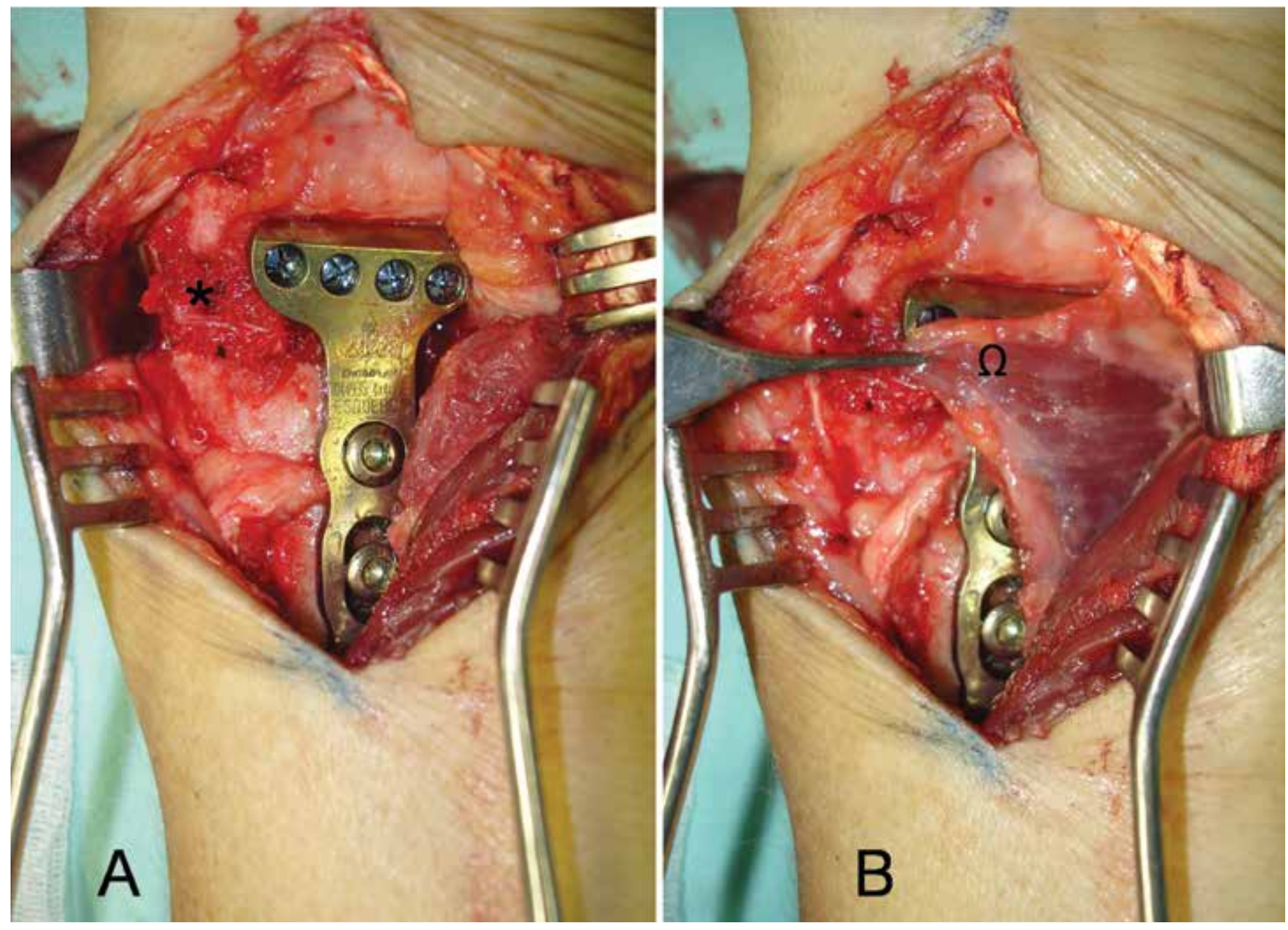

Figure 9 - View after placement of the fixed-angle volar plate for fixation of the osteotomy $(A)$. Note the filling of the bone stretching location with a spongy-cortical graft taken from the iliac $\left(^{*}\right)$. In Figure B, note the covering of the synthesis material by the pronator quadratus muscle, which protects the flexor tendons and median nerve.

\section{RESULTS}

From a clinical point of view, the patients presented a great improvement in symptoms. The mean on the analogue pain scale went from 8.1 to 2.3 during the postoperative period (with a range from 1 to 4 during the postoperative period), which was a statistically significant improvement $(\mathrm{p}<0.0001)$.

The patients' mean wrist extension increased significantly, from $36.3^{\circ}$ (range: $28-50^{\circ}$ ) before the operation to $60.3^{\circ}$ after the operation (range: $\left.45-70^{\circ}\right)(\mathrm{p}<$ $0.001)$. The mean wrist flexion increased from $23.1^{\circ}$ (range: $15-35^{\circ}$ ) before the operation to $43^{\circ}$ after the operation (range: $\left.40-55^{\circ}\right)(\mathrm{p}<0.0001)$. The mean supination after the operation was $70.2^{\circ}$ (range: $55-85^{\circ}$ ), which was a significant increase in relation to before the operation, which was a mean of $46.7^{\circ}$ (range: $35-$ $\left.65^{\circ}\right)(\mathrm{p}<0.0001)$. The mean pronation increased from $58.2^{\circ}$ (range: $45-75^{\circ}$ ) before the operation to $80^{\circ}$ after the operation (range: $\left.65-90^{\circ}\right)(\mathrm{p}<0.001)$.

Grip strength was measured using a Lamar dynamometer placed at setting 3. After the operation, grip strength was significantly greater, going from a mean of $13.4 \mathrm{lbs}$ (range: $8-20 \mathrm{lbs}$ ) to a mean of 34.5 lbs (range: $26-53 \mathrm{lbs})(\mathrm{p}<0,0001)$.

With regard to complaints of numbness and tingling in the area innervated by the median nerve, carpal tunnel release was performed only in the patients who had presented symptoms prior to the fracture. All the patients who were operated achieved improvements regarding their nerve compression complaints.

The DASH questionnaire was not applied to all of the patients after the operation, and complete evolution was only recorded in the cases of 11 of the 20 patients. Among these patients, the mean score was 62 before the operation (range: 24-83) to 11 after the operation (range: 2-28). 
From a radiographic point of view, the mean dorsal angle of the radius was $27.2^{\circ}$ (range: $15-40^{\circ}$ ) before the operation to a volar angle of $6.2^{\circ}$ after the operation (range: $\left.1-13^{\circ}\right)(\mathrm{p}<0.0001)$. The mean ulnar angle of the radius was $87^{\circ}$ (range: $74-98^{\circ}$ ) before the operation to $69.3^{\circ}$ after the operation (range: $62-75^{\circ}$ ) $(p<0.0001)$. The mean shortening of the radius was $7.3 \mathrm{~mm}$ (range: $4-10$ ) before the operation to $1.1 \mathrm{~mm}$ after the operation (range: $0-3)(p<0.0001)$.

There was no significant difference in the radiographic indices between assessments in the immediate postoperative period and after complete evolution.

At the time of the final assessment, with a mean follow-up of 43.9 months (range: 12-96 months), all the patients presented bone consolidation at the fracture sites. The mean time taken for consolidation to be achieved, as seen in radiological examination, was 8.5 weeks (range: 6-16 weeks) (Figure 10 - A and B).

There were no complications relating to absence or breakage of synthesis material or loss of the bone correction that had been obtained (Figure $11-\mathrm{A}$ and $\mathrm{B}$ ). There were also no severe complications such as deep infection or neurotendinous lesions. There was no need for a second procedure relating to complications consequent to the fracture or to tendon irritation caused by the synthesis material.

Although five patients demonstrated moderate degenerative alterations on postoperative radiographs, particularly with long-term follow-up, there were no clinical repercussions like pain, loss of strength or loss of mobility.
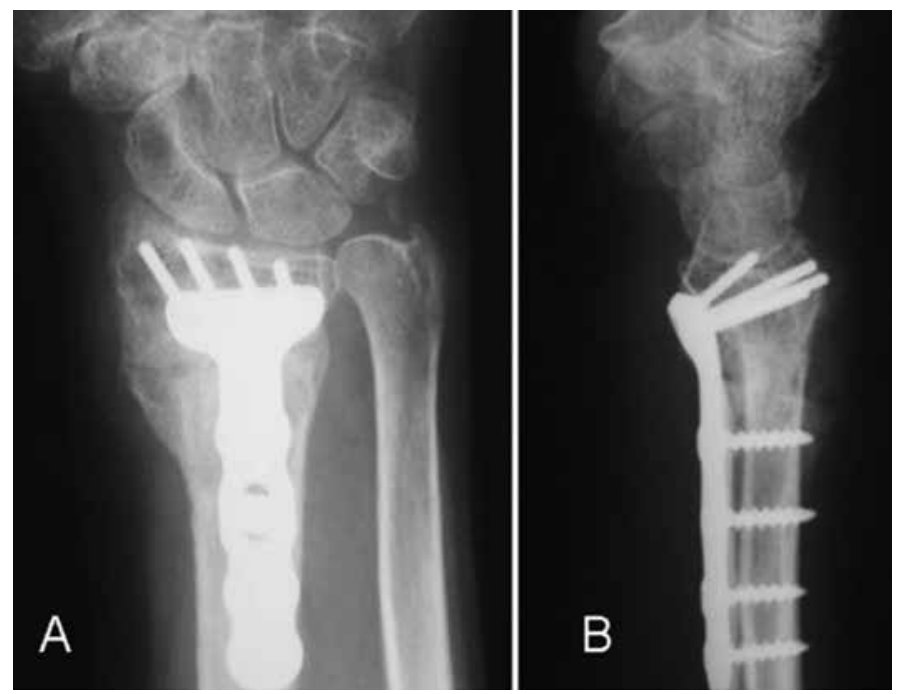

Figure 10 - Three months after the operation. Anteroposterior radiograph $(A)$ showing consolidation with $2 \mathrm{~mm}$ of radial shortening; and lateral radiograph $(\mathrm{B})$ showing complete recovery of the volar angle of the distal radius (15 degrees).
Postoperative physiotherapy was indicated starting four weeks after the osteotomy, for all the 20 patients. Of these, five did not do the rehabilitation with a trained professional, for personal reasons. All of the patients achieved full mobility of their fingers; i.e. they remained able to touch the distal flexor crease of the palm with the pulp of the fingers. There was no statistically significant difference between the patients who did and those who did not do physiotherapy, when assessed after long evolution (more than 12 months).

At the time of the final assessment, the functional evaluation was done in accordance with the Gartland and Werley scale ${ }^{(17)}$, from which 16 cases were considered to be excellent and four, good.

To assess the esthetics, the Frykman scale was used, and $100 \%$ of the cases were considered to be

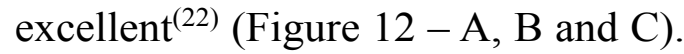

\section{DISCUSSION}

Deformity of the distal radius may give rise to biomechanical changes to the carpus and radiocarpal joint. Restoration of the length and angulation is often a challenge ${ }^{(23)}$. When there is a dorsal angle in the sagittal plane greater than $20^{\circ}$, the contact surfaces and load axes undergo dorsal translation, thus giving rise to dorsal subluxation of the first row of the carpus, which increases the load per surface unit at the level of this joint by $50 \%$, with a dorsal tilt of $20 \%$, and reaches $67 \%$ with dorsal deformity of 45 degrees $^{(12)}$. Thus, a change in

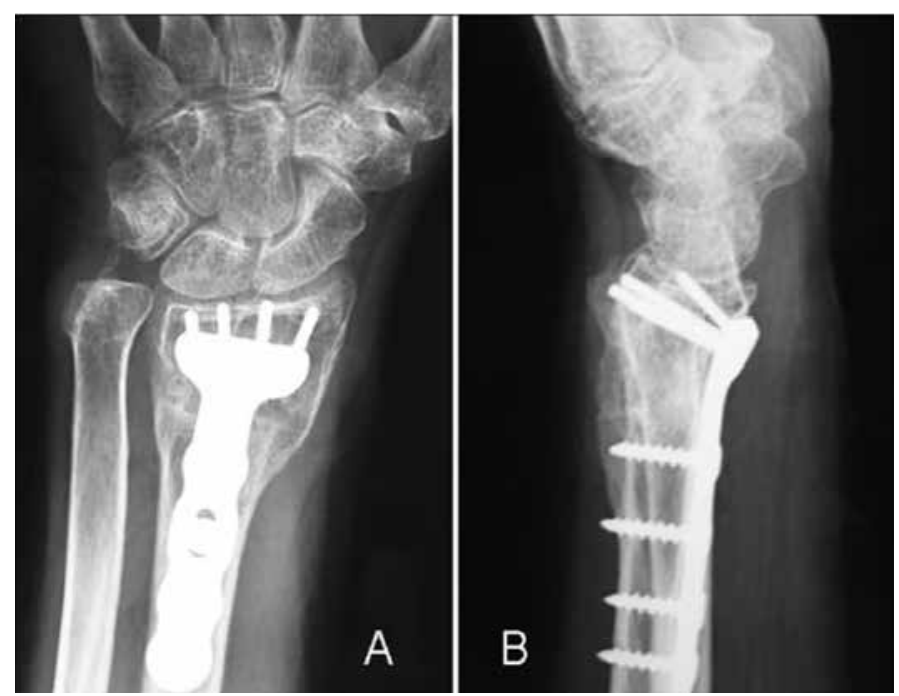

Figure 11 - Radiographs produced after 12 months of postoperative evolution, in anteroposterior view $(A)$ and lateral view $(B)$, demonstrating that the reduction parameters obtained during the operation were maintained. 


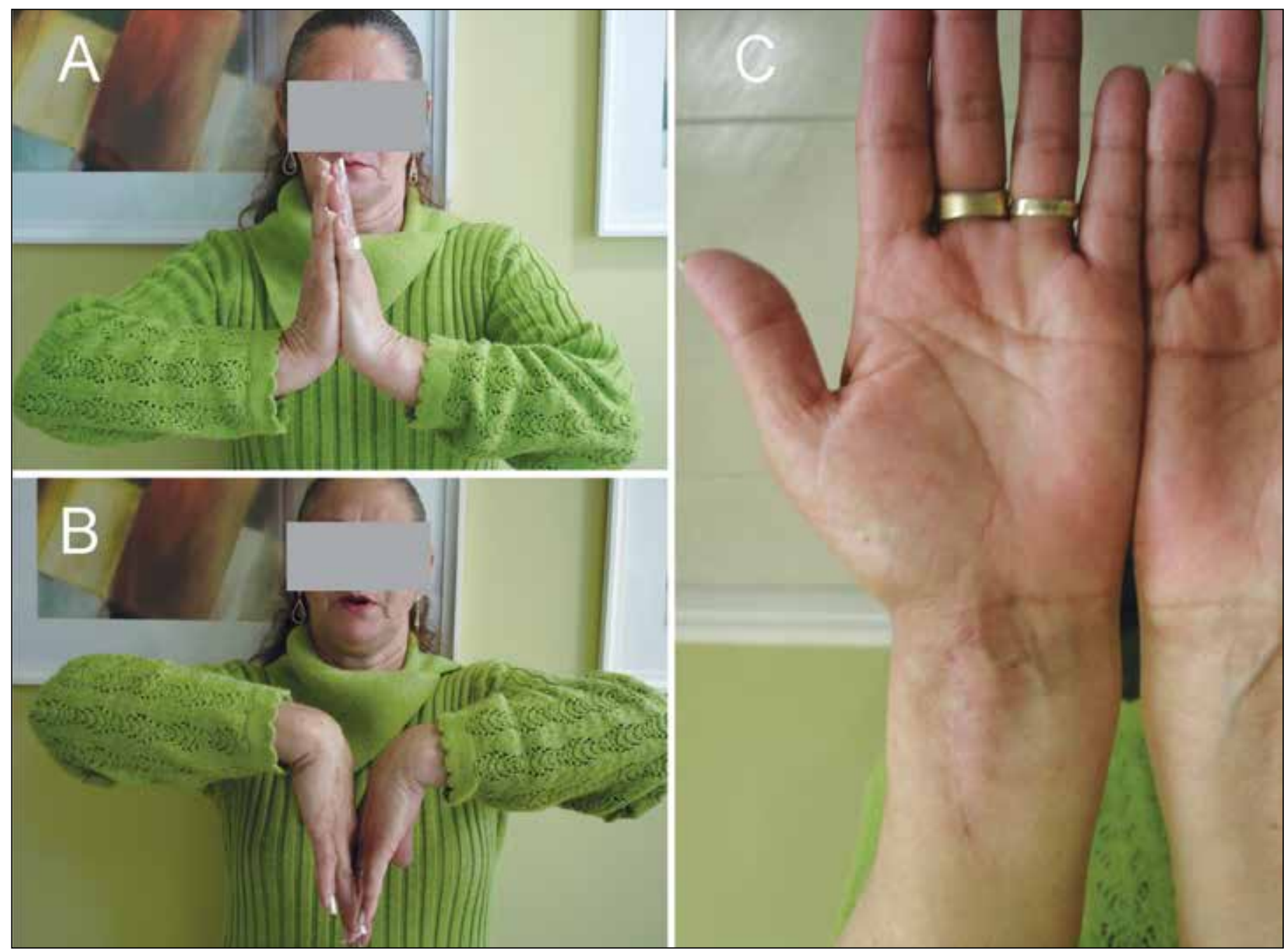

Figure 12 - Assessment of wrist mobility after 12 months of postoperative evolution. Extension of 60 degrees (A) and flexion of 80 degrees $(B)$. Note the excellent esthetic recovery of the volar incision to the distal radius, after one year of evolution (C).

the center of rotation of the wrist is generated, which influences the normal translation of the tendons and reduces their lever arm, thereby causing a loss of strength of $50-60 \%$ in relation to the contralateral $\operatorname{limb}^{(10,24)}$.

Skewed consolidation in association with shortening of the radius gives rise to a discrepancy in the distal radioulnar joint. Under normal conditions, 17\% of the axial load acting on the wrist is located on the ulnocarpal joint ${ }^{(25)}$. Stretching of the ulna in relation to the radius gives rise to an additional, reaching $42 \%$ of the axial load in deformities with positive variance of $2.5 \mathrm{~mm}^{(26)}$. The incongruence generated negatively influences the range of motion of the distal radioulnar joint and may cause reduction of forearm rotation by $47 \%$ in pronation and $29 \%$ in supination ${ }^{(27)}$.

The commonest symptom of extra-articular skewed consolidation is pain. This may occur in the radiocarpal, distal radioulnar or mediocarpal joint. Loss of movement and weakness of the wrist are often noted. Other complications from skewed consolidation of the radius include tendon tearing - most frequently of the long extensor of the fingers - and compression of the median nerve $\mathrm{e}^{(2)}$.

The need for correction of deformities in cases of fractures of the distal radius that present symptomatic skewed consolidation is not a new concept. In 1932, Ghormley and $\mathrm{Mroz}^{(28)}$ described surgical correction of a deformity of the radius and, in 1946, Speed and Knight $^{(23)}$ presented treatment for skewed consolidation of the distal radius by means of a graft from the iliac crest and internal fixation. Nonetheless, the reference technique over the last few years has been the one described by Fernandez in the 1980s ${ }^{(29)}$.

Because it is known that unstable fractures may become displaced, and because reliable new fixation systems for the distal radius have appeared, surgical treatment for distal radius fractures has become refined, 
thus diminishing the incidence of skewed consolidation.

Different authors have used different approached for correcting the deformities, using dorsal and volar osteotomy to correct the deformity. Anatomical and imaging studies have demonstrated that the volar region of the distal portion of the radius has greater space, which makes it possible to emplace synthesis material. Furthermore, the distal and volar portions of the radius are anatomically planar, which facilitates bone fixation. This location is mechanically favorable for this fixation, as well as avoiding complications with flexor and extensor tendons, and removal of the synthesis material is unnecessary. Using an extended approach from the FCR makes it possible to fully view the operative field and facilitates carrying out the osteotomy that had previously been planned ${ }^{(18,30-32)}$.

It is clear that the best time for treating distal radius fractures is in the acute phase. There is less morbidity and the results are better, especially compared with the results obtained from treating sequelae (skewed consolidation), which requires a longer immobilization period and a second associated procedure, such as bone graft harvesting from the iliac crest, thereby increasing the morbidity. In agreement with the literature, our series also confirms that most patients who evolve to skewed consolidation of the distal radius are initially treated conservatively (orthopedically).

Misalignment of the fragments of distal radius fractures and their subsequent skewed consolidation may occur in all three spatial axes: sagittal, originating dorsal or volar angulation (less frequently); coronal or frontal, through collapse of the radial column; and axial, through rotation of a distal fragment in supination, in fractures with dorsal angulation, or in pronation if the angulation is volar ${ }^{(5)}$. Just as joint steps greater than $2 \mathrm{~mm}$ are considered to be precursors of arthrosis, sagittal angulation of the distal radius greater than $20^{\circ}$ or shortening greater than $4 \mathrm{~mm}$ also give rise to degenerative processes in the joint and should be treated surgically in young patients.

According to Fernandez ${ }^{(29)}$, for patients treated by means of osteotomy of the distal radius, there should be an associated procedure to save the distal radioulnar joint. This author took the view that correct alignment of the distal radius during osteotomy would not produce sequelae in the distal radioulnar joint. For this reason, and because of the absence of symptoms of instability in our series, we did not perform any associated procedures on the distal radioulnar joint during the osteotomy on the radius.

By using a volar approach for performing osteotomy, it become possible to release the pronator quadratus muscle. This is often shortened due to tearing and subsequent fibrosis, caused by the fracturing of the distal radius ${ }^{(18)}$. For this reason, almost complete recovery of supination was justifiable in our group of patients. Moreover, the volar approach enabled release and stretching of the volar portion of the distal radioulnar fragments that were found to be shortened.

Differing from other series that we reviewed, which showed heterogenous groups of patients (both young and old adults) and different deformity characteristics (intra or extra-articular), our group of patients was as homogenous as possible, formed by patients with similar deformities and fractures. Like the published results from previous series, our results show that volar fixation systems for the radius present lower complication rates than do those with dorsal fixation. This incidence diminishes the need for a second surgical procedure for removing the synthesis material or performing neurotendinous repairs ${ }^{(33)}$.

A new technique for performing corrections on dorsal deformities of the radius by means of a conventional volar approach expanded to the FCR was recently described ${ }^{(20)}$. The distal extremity of the radius was fixed by means of a fixed-angle implant and proximal osteotomy was performed on the distal radius. Through the same approach, a compacted spongy bone graft was introduced to fill the bone defect that had been created. In this manner, the need for a second approach to place the bone graft and fix it with dorsal implants was avoided.

Internal fixation systems for osteotomy procedures using plates with locking screws, in which the distal screws are fixed with a plate, reduces the risk of losing the bone alignment after the operation and does not require such a long immobilization time. In many cases, conventional fixation systems do not have the capacity to bear the loads and other associated fixation methods, such as an external fixator, are required ${ }^{(34)}$.

Fixed-angle implants were used in all of our cases of volar osteotomy. We agree with Von Campe et $\mathrm{al}^{(35)}$, who reported that with fixed-angle fixation systems, small changes in angulation can be made during the surgery, thus differing from other, more traditional 
methods, which require preoperative planning and very precise graft fragments in order to maintain the corrective osteotomy in the right position.

Jupiter and Ring ${ }^{(30)}$ demonstrated that performing early osteotomy facilitates the surgical procedure (osteotomy by means of immature bone tissue, with less soft-tissue retraction and less instability of the distal radioulnar joint) and diminishes the time off work. For this reason, young patients with dorsal angulation greater than $20^{\circ}$ should be considered to be in a precursor situation of the degenerative process (arthrosis), and a surgical procedure should be indicated.

\section{CONCLUSION}

We can affirm that treatment for skewed consolidation of the distal radius by means of extra-articular corrective osteotomy using a fixed-angle volar plate produ- ces satisfactory clinical and radiological results among symptomatic patients, like in the series presented.

Our results obtained using a fixed-angle volar plate are good compared with other series of similar lesions that were treated with other types of fixation. We believe that these positive results were due to the lower damage to tendons and the release of the pronator quadratus muscle, in comparison with the dorsal approach. This could be seen through the rapid postoperative return to functioning and the low need for physiotherapy.

For these reasons, we believe that it is possible, through using fixed-angle volar plates, to routinely manage severe deformities due to sequelae from distal radius fractures, by means of stable fixation and early mobilization of the wrist. Because of the rapid functional recovery, this form of treatment can be considered to be beneficial for all adult patients, including those with lower demands and elderly patients.

\section{REFERENCES}

1. Colles A. On the fracture of the carpal extremity of the radius. Edinb Med Surg J. 1814;10:1813-5

2. Sharpe $F$, Stevanovic M. Extra-articular distal radial fracture malunion. Hand Clin. 2005;21(3):469-87.

3. Cooney WP 3rd, Dobyns JH, Linscheid RL. Complications of Colles' fractures. J Bone Joint Surg Am. 1980;62(4):613-9.

4. De Pedro JA, Blanco J, De Cabo A, Garcia de Lucas F, Martin AP, Persson I, et al. Resultados del tratamiento quirúrgico de las fracturas del radio distal. Rev Ortop Traumatol. 2004;48(Supl 1):83-7.

5. Albertoni WM, Faloppa F, Belotti JC. Tratamento das fraturas da extremidade distal do rádio. Rev Bras Ortop. 2002; 37(1):1-4.

6. Jupiter J, Fernandez D. Complications following distal radial fractures $\mathrm{J}$ Bone Joint Surg Am. 2001;83(1):1244-65.

7. Knirk JL, Jupiter JB. Intra-articular fractures of the distal end of the radius in young adults. J Bone Joint Surg Am. 1986;68(5):647-59.

8. Pino J, Bartolomé del Valle E, López Graña G, Ferreira Villanova J. Consolidaciones viciosas tras fracturas del extremo distal del radio: patogenia, indicaciones y técnicas quirúrgicas. Rev Ortop Traumatol. 2003;47(Supl 1):55-69.

9. Earnshaw SA, Aladin A, Surendran S, Moran CG. Closed reduction of colles fractures: comparison of manual manipulation and finger-trap traction: a prospective, randomized study. J Bone Joint Surg Am. 2002;84(3):354-8.

10. Prommersberger KJ, Van Schoonhoven J, Lanz UB. Outcome after corrective osteotomy for malunited fractures of the distal end of the radius. J Hand Surg Br. 2002;27(1):55-60.

11. Fernandez DL. Radial osteotomy and Bowers arthroplasty for malunited fractures of the distal end of the radius. J Bone Joint Surg Am. 1988;70(10):1538-51.

12. França Bisneto EN, Paula EJL, Resende MR, Mattar Júnior R, Zumiotti AV. Fratura distal do rádio em pacientes com mais de 60 anos: placas ortogonais versus placa volar. Rev Bras Ortop. 2010;45(6):590-5.

13. Prommersberger KJ, Lanz U. Corrective osteotomy for malunited Colles fractures. Orthop Traumatol. 1998;6:75-87.

14. Fernandez DL, Jupiter JB. Fractures of the distal radius. A practical approach to management. New York: Springer-Verlag; 1995.

15. Castaing J. Les fractures récentes de l'extremité inférieure du radius chez l'adulte. Rev Chir Orthop. 1964;50:581-696.

16. Fernandez DL. Fractures of the distal radius: operative treatment. Instr Course Lect. 1993;42:73-88.

17. Gartland JJ Jr, Werley CW. Evaluation of healed Colles' fractures. J Bone Joint Surg Am. 1951;33(4):895-907.

18. Orbay J, Badia A, Khoury RK, Gonzalez E, Indriago I. Volar fixed-angle fixation of distal radius fractures: the DVR plate. Tech Hand Up Extrem Surg. 2004;8(3):142-8.

19. Orbay JL, Fernandez DL. Volar fixation for dorsally displaced fractures of the distal radius: a preliminary report. J Hand Surg Am. 2002;27(2):205-15.

20. Prommersberger KJ, Lanz UB. Corrective osteotomy of the distal radius through volar approach. Tech Hand Up Extrem Surg. 2004;8(2):70-7.

21. Milch $\mathrm{H}$. Cuff resection of the ulna for malunited Colles fractures. J Bone Joint Surg Am. 1941;23(2):311-3.

22. Frykman G. Fracture of the distal radius including sequelae - shoulder handfinger syndrome, disturbance in the distal radio-ulnar joint and impairment of nerve function. A clinical and experimental study. Acta Orthop Scand. 1967;(Suppl 108): 3+.

23. Speed JS, Knight RA. The treatment of malunited Colles's fractures. J Bone Joint Surg. 1945;27(3):361-7.

24. Shea K, Fernandez DL, Jupiter JB, Martin C Jr. Corrective osteotomy for malunited, volarly displaced fractures of the distal end of the radius. J Bone Joint Surg Am. 1997;79(12):1816-26.

25. Iwasaki N, Minami A, Miyazawa T, Kaneda K. Force distribution through the wrist joint in patients with different stages of Kienböck's disease: using computed tomography osteoabsorptiometry. J Hand Surg Am. 2000;25(5):870-6.

26. Werner FW, Palmer AK, Fortino MD, Short WH. Force transmission through the distal ulna: effect of ulnar variance, lunate fossa angulation, and radial and palmar tilt of the distal radius. J Hand Surg Am. 1992;17(3):423-8.

27. Bronstein AJ, Trumble TE, Tencer AF. The effects of distal radius fracture malalignment on forearm rotation: a cadaveric study. J Hand Surg Am. 1997;22(2):258-62.

28. Ghormley RK, Mroz RJ. Fractures of the wrist. A review of one hundred seventysix cases. Surg Gynec Obstet. 1932;57:377-81.

29. Fernandez DL. Correction of post-traumatic wrist deformity in adults by osteotomy, bone-grafting, and internal fixation. J Bone Joint Surg Am. 1982;64(8):1164-78.

30. Jupiter JB, Ring D. A comparison of early and late reconstruction of malunited fractures of the distal end of the radius. J Bone Joint Surg Am. 1996;78(5):739-48.

31. Linder L, Stattin J. Malunited fractures of the distal radius with volar angulation: corrective osteotomy in 6 cases using the volar approach. Acta Orthop Scand. 1996;67(2):179-81.

32. Kamano M, Honda Y, Kazuki K, Yasuda M. Palmar plating for dorsally displaced fractures of the distal radius. Clin Orthop Relat Res. 2002;(397):403-8.

33. Kambouroglou GK, Axelrod TS. Complications of the AO/ASIF titanium distal radius plate system (pi plate) in internal fixation of the distal radius: a brief report. J Hand Surg Am. 1998;23(4):737-41.

34. Ring D, Roberge C, Morgan T, Jupiter JB. Osteotomy for malunited fractures of the distal radius: a comparison of structural and nonstructural autogenous bone grafts. J Hand Surg Am. 2002;27(2):216-22.

35. von Campe A, Nagy L, Arbab D, Dumont CE. Corrective osteotomies in malunions of the distal radius: do we get what we planned? Clin Orthop Relat Res. 2006;450:179-85. 